\title{
Conselhos Municipais de Assistência Social: novas competências para o trabalho do assistente social
}

\author{
Angela Vieira Neves \\ Universidade de Brasília (UnB)
}

Cláudia de Oliveira Vicente Santos

Universidade de Brasília (UnB)

\author{
Suellem Henriques da Silva \\ Universidade de Brasília (UnB)
}

\begin{abstract}
Conselhos Municipais de Assistência Social: novas competências para o trabalho do assistente social

Resumo: Este artigo apresenta os resultados de uma pesquisa sobre os Conselhos Municipais de Assistência Social (CMAS) e a inserção dos assistentes sociais nesses espaços públicos no estado do Rio de Janeiro. Seu objetivo é trazer contribuições ao debate sobre as demandas impostas aos profissionais em Serviço Social frente aos conselhos gestores de políticas públicas e, mais especificamente, aos Conselhos Municipais de Assistência Social. Os procedimentos metodológicos combinaram um levantamento realizado através de pesquisa bibliográfica e documental de dados secundários, questionários aplicados por e-mail e consultas por telefone junto às secretarias de assistência social dos 92 municípios que compõem o estado do Rio de Janeiro, durante o período de setembro de 2010 a junho de 2011. Através dos dados levantados, foi possível concluir que há um aumento da participação dos assistentes sociais no espaço dos conselhos, principalmente a partir de 2000, quando lhes são atribuídas novas competências, aprofundando e qualificando sua atuação junto à gestão das políticas públicas.
\end{abstract}

Palavras-chave: Conselho Municipal de Assistência Social. Serviço Social. Participação.

\section{Municipal Social Assistance Councils: New Competencies for the Work of the Social Worker}

Abstract: This article presents the results of a study about Municipal Social Assistance Councils (CMAS) and the insertion of social workers in these public spaces in Rio de Janeiro State. Its objective is to contribute to the debate about the demands placed on Social Work professionals in relation to councils that administer public policies, and more specifically, the Municipal Social Assistance Councils. The methodological procedures combine a bibliographic and documental study of secondary data with questionnaires presented by e-mail and telephone consultations with the social assistance secretariats at 92 municipalities in Rio de Janeiro State, from September 2010 - June 2011. Through the data surveyed, it was possible to conclude that there has been an increase in the participation of social workers on the councils, particularly since 2000 , when they were given new competencies, deepening and qualifying their work in the administration of public policies.

Keywords: Municipal Social Assistance Council. Social Work. Participation. 


\section{Introdução}

As décadas de 1970 e 1980 no Brasil foram marcadas pelo ressurgimento da participação popular decorrente do "confronto" entre a sociedade civil e o Estado autoritário durante o regime militar. Segundo Lenardão (1999, p. 59), esses movimentos sociais " [...] foram responsáveis pela ampliação da presença de setores das classes populares na vida política brasileira". Essa abrangência de atores sociais possibilitou uma postura crítica e ampliada na luta social que objetivava o reconhecimento dos direitos sociais, políticos e civis.

O processo de redemocratização do Estado brasileiro trouxe como resposta a elaboração da Constituição Federal de 1988, que reconheceu direitos de cidadania, o Estado como gestor das políticas sociais, além de prever a participação popular nas decisões do poder público.

Nas últimas décadas, a política de assistência vem sendo implementada em um contexto adverso marcado por projetos políticos antagônicos ${ }^{1}$. São projetos nos quais se verifica a existência de uma situação de perversidade no fato de que, apontando para direções opostas, requerem uma sociedade civil ativa e propositiva (DAGNINO, 2004). Neste contexto, a participação da sociedade civil encontra amparo legal no âmbito da assistência social. A Lei Orgânica da Assistência Social (LOAS, BRASIL, 1993a), no seu artigo 5, por exemplo, além de direcionar a Política Nacional de Assistência Social (PNAS, BRASIL, 2004) no campo da execução também a favorece no campo da formulação, prevendo a "participação da população, por meio de organizações representativas, na formulação das políticas e no controle das ações em todos os níveis."

Esta pesquisa, e especificamente a pesquisa mais ampla na qual está inserida ${ }^{2}$, direciona-se à participação da sociedade civil em âmbito municipal, através dos Conselhos Municipais de Assistência Social, os quais, segundo Bidarra (2005, p. 7-8),

[...] previstos na LOAS, Art. 9., são instâncias corresponsáveis pelo estabelecimento de diretrizes, pelo planejamento, acompanhamento da execução e pela fiscalização das ações assistenciais desenvolvidas por órgãos governamentais e por entidades sociais [...].

Mas, de acordo com a autora, "os Conselhos Municipais não podem ser observados apenas pela colaboração que fornecem" no que se refere à administração da PNAS, pois "Ante qualquer prerrogativa, eles são espaços de construção social das relações políticas de suas respectivas comunidades". Assim, o que se pretende é a transformação das práticas políticas. Para tanto, devem abrir espaço para a interlocução e a negociação entre as várias tendências presentes, prática necessária para o aprofundamento da experiência democrática que possa explicitar, sem constrangimentos, ideias e intencionalidades sobre as matérias que são objetos de deliberação (BIDARRA, 2005).

Os conselhos gestores de assistência social ao longo dos anos adquiriram o caráter deliberativo/consultivo e paritário, como "[...] instâncias em que se refratam interesses contraditórios e, portanto, espaços de lutas e disputas políticas" (IAMAMOTO, 2009, p. 360). Foi a partir da década de 1990 que a participação popular passou a se caracterizar como uma participação negociada na disputa entre os projetos distintos e não mais como um confronto entre sociedade civil e Estado. Neves (2006, 2008) afirma que há um processo de institucionalização da participação popular, evidenciando a estreita aproximação entre governo local e a população.

É neste contexto que este artigo vem contribuir para desvendar o que hoje se denomina "controle democrático", promovido pela participação nos Conselhos Municipais de Assistência Social, e para expor os embates que essa questão produz para o exercício do assistente social no debate contemporâneo da profissão.

\section{Aspectos metodológicos}

A metodologia aplicada a esta pesquisa compreendeu duas etapas: a primeira com o levantamento de dados secundários, realizado através de pesquisas bibliográfica e documental nos sítios on-line do Ministério de Desenvolvimento Social e Combate à Fome (BRASIL, 2012a) e do Instituto Brasileiro de Geografia e Estatística (BRASIL, 2012b). A segunda etapa incluiu a pesquisa de dados primários, realizada através de questionários enviados por correio eletrônico para os Conselhos Municipais de Assistência Social dos 92 municípios que compõem o Estado do Rio de Janeiro. Todos os contatos foram abordados por telefone ou correio eletrônico e concordaram previamente em participar desta pesquisa respeitando as questões éticas do sigilo e do anonimato. Todos os participantes contatados foram devidamente esclarecidos e consentiram em participar livremente deste trabalho. O levantamento de fontes secundárias bem como a aplicação do questionário compreendeu o período de setembro de 2010 a junho de 2011.

\section{Perfil dos Conselhos Municipais de Assistência Social do Rio de Janeiro}

Seguindo a proposta de tornar o Estado e a sociedade civil democráticos - com a progressiva 
participação da sociedade na definição das políticas e a visibilização de ações que se dão a partir do Estado - os conselhos gestores vêm expressar a possibilidade de ampliação e ressignificação da própria democracia por trabalharem na construção de uma nova cultura participativa da sociedade na esfera da política.

Os conselhos gestores estão previstos em legislação e são considerados parte integrante do sistema nacional, com atribuições legalmente estabelecidas, no plano da formulação e implementação das políticas na respectiva esfera governamental (municipal, estadual e federal), compondo as práticas de planejamento e fiscalização das ações. São também concebidos como fóruns públicos de captação de demandas e de negociação de interesses específicos dos diversos grupos sociais como uma forma de ampliar a participação dos segmentos com menos acesso ao aparelho do Estado. Nesta perspectiva, Gomes (2000, p. 166) destaca que:

Os conselhos são considerados condutos formais de participação social, institucionalmente reconhecidos, com competências definidas em estatuto legal, com o objetivo de realizar o controle social de políticas públicas setoriais ou de defesa de segmentos específicos. Sua função é garantir, portanto, os princípios da participação da sociedade nos processos de decisão, definição e operacionalização das políticas públicas, emanadas da Constituição.

Esses instrumentos são hoje uma realidade consolidada através de décadas de lutas sociais na afirmação da cidadania. No entanto, deve-se ressaltar que nesses espaços estão presentes diversos projetos que contribuem para direcionar sua ação. A pesquisa realizada buscou traçar as características dos conselhos municipais e sua relação com o trabalho do assistente social.

\section{O papel do assistente social nos Conselhos Municipais de Assistência Social}

Ao longo do tempo os assistentes sociais estiveram predominantemente na posição de executores de políticas sociais. Embora essa atuação ainda seja uma característica marcante e intrínseca do seu trabalho, pois sua intervenção profissional incide sobre as múltiplas expressões da questão social, atualmente esses profissionais são chamados a ocupar novos espaços de trabalho, como os dos conselhos gestores de políticas.

A atuação dos assistentes sociais junto aos conselhos gestores tem se ampliado, com destaque para os conselhos de saúde e de assistência social. Esse fenômeno deve-se, em grande medida, à "inserção privilegiada" do Serviço Social no âmbito das políticas sociais, desenvolvendo, principalmente, um trabalho de alta relevância nas políticas da Seguridade Social, em sua execução, planejamento, gestão, monitoramento e avaliação. A "inserção privilegiada" do assistente social junto às políticas de proteção social refere-se à particularidade interventiva do profissional em lidar cotidianamente com as "múltiplas e diversificadas expressões da questão social" (IAMAMOTO, 2010, p. 198).

A descentralização e a municipalização das políticas públicas vêm ampliando o mercado de trabalho para os assistentes sociais. Com isso abrem-se novos canais de atuação profissional ${ }^{3}$ que não se restringem apenas à execução, mas também à formulação e gestão das políticas sociais. É por essa nova demanda que Iamamoto (1998) destaca a exigência de um trabalhador qualificado, apto para responder às novas e às antigas atribuições.

De acordo com CFESS (2005, p. 46-47), em pesquisa publicada em 2005 sobre o perfil dos assistentes sociais no Brasil, destaca-se uma parcela relativamente pequena, mas em crescimento, de profissionais com participação em conselhos (representantes governamentais, representantes dos profissionais, assessores).

[...] a participação da (o) assistente social nos conselhos de direitos ou de políticas sociais indica o exercício do 'controle social', o que implica o exercício democrático de acompanhamento da gestão e avaliação da política, do plano da política e dos recursos financeiros destinados à sua implementação.

A pesquisa também revelou que um terço desses profissionais concentra-se nos Conselhos de Assistência Social, representando um indicador significativo.

Ainda, segundo CFESS (2010, 2011), a profissão presencia uma série de novas competências, estratégias e novos procedimentos no trabalho do assistente social, dando destaque para a participação e a atuação nos conselhos municipais, estaduais e nacional na condição de conselheiro ou secretário executivo e a prestação de assessoria, na perspectiva de fortalecimento do controle democrático e da ampliação da participação de usuários e trabalhadores.

Dessa forma, a análise da participação do assistente social nos CMAS deve considerar os pilares éticos, teórico-metodológicos e sócio-históricos que fundamentam a direção sociopolítica do Serviço Social na atualidade. A referência desse conteúdo ideológico e político é o projeto ético-político profissional hegemônico na profissão a partir da década de 1980, representando um marco do movimento de ruptura 
do Serviço Social com o tradicional conservadorismo na profissão (PAULO NETTO, 1999).

A atuação dos assistentes sociais nesses espaços é importante para enfatizar sua dimensão educativa e a busca na consolidação de direitos pela participação em espaços públicos. Percebe-se que a preocupação com a ocupação dos assistentes é crescente. De acordo com a tabela 1 , dos 92 conselhos pesquisados, 90,2\% (83) relataram ter assistente social atuando das mais diversas formas, como representante governamental, representante da sociedade civil, assessor, consultor, secretário executivo ou secretário administrativo.
A ocupação nesses espaços é fruto da abertura progressiva e do reconhecimento dos conselhos como espaços sócio-ocupacionais do assistente social.

Segundo a tabela 2, o número de assistentes sociais é bastante diversificado, variando de um até oito, sendo o percentual mais expressivo àquele correspondente a um assistente social por conselho com $46,9 \%$, seguido de dois assistentes sociais por conselho em $32,5 \%$ dos CMAS. Apenas nove municípios informaram não possuir assistente social em seu conselho.

A ocupação do assistente social no espaço dos CMAS é variada. Na tabela 3 , destacamos quatro formas: representante governamental, representante

Tabela 1 - Número de municípios com assistente social em CMAS

\begin{tabular}{|c|c|c|}
\hline Municípios & Quantidade & \% \\
\hline CMAS com assistente social & 83 & 90,2 \\
\hline CMAS sem assistente social & 9 & 9,8 \\
\hline Total & $\mathbf{9 2}$ & $\mathbf{1 0 0 , 0}$ \\
\hline
\end{tabular}

Fonte: elaborada pelas pesquisadoras.

Tabela 2 - Número de assistentes sociais por CMAS

\begin{tabular}{|c|c|c|}
\hline Número de assistentes sociais & Quantidade de CMAS & \% \\
\hline 1 & 39 & 46,9 \\
\hline 2 & 27 & 32,5 \\
\hline 3 & 13 & 15,6 \\
\hline 4 & 1 & 1,2 \\
\hline 5 & 2 & 2,4 \\
\hline ou + & 1 & 1,2 \\
\hline
\end{tabular}

Fonte: elaborada pelas pesquisadoras.

Tabela 3 - Atuação dos assistentes sociais nos CMAS

\begin{tabular}{|ccc|}
\hline Vínculo & Quantidade de assistentes sociais & \% \\
\hline Representante governamental & 74 & 48,6 \\
\hline Representante da soc. civil & 36 & 23,6 \\
\hline Assessor/consultor & 25 & 16,4 \\
\hline Sec. executivo/administrativo & 17 & 11,1 \\
\hline Total & $\mathbf{1 5 2}$ & $\mathbf{1 0 0 , 0}$ \\
\hline
\end{tabular}

Fonte: elaborada pelas pesquisadoras. 
da sociedade civil, assessor/consultor e secretário executivo/administrativo.

Para esta análise, foram consideradas as três primeiras formas de ocupação.

\subsection{Assistente social como representante governamental}

Segundo a pesquisa, do total de 152 assistentes sociais em CMAS, quase metade $(48,6 \%)$ ocupa a função de representante governamental.

Nessa perspectiva, a inserção do assistente social nos CMAS não é exclusivamente na condição de cidadão político, mas também como trabalhador de Serviço Social. Seu trabalho não deve se distinguir daquele de participação do assistente social como representante da sociedade civil. Assistentes sociais na posição de conselheiros governamentais que direcionam sua atuação à militância política, à defesa de projetos político-partidários ou que contribuem para reproduzir os conflitos entre os governantes e governados, distanciam-se do projeto ético-político profissional.

Iamamoto (2010, p. 229-230) destaca o cuidado a ser tomado pelas pesquisas, para não regredir a análise e as projeções profissionais à proposta da década de 1980, quando a atuação profissional foi reduzida à "militância política":

[...] a dimensão política da profissão não se confunde com o partido político - trata-se de uma categoria cravejada por diferenças sociais e ideológicas e, muito menos, com as relações de poder entre governados e governantes, ainda que o assistente social também possa exercer funções de governo. É nesse sentido que se reclama a autonomia do projeto profissional perante os partidos e o governo. Mas não se trata, também, de reduzi-lo à pequena política ou à contrapolítica dos técnicos, que se pretende asséptica e neutra, mas afirma o instituído. Outrossim, sua efetivação implica a decisão de ultrapassar a pequena política do dia a dia, [...], que se traduz no empirismo, nas rotinas, no burocratismo, que frequentemente se repõem no trabalho profissional.

Historicamente, sabe-se que os profissionais do Serviço Social foram requisitados pelo Estado brasileiro para dar base técnica às ações da assistência. Porém, é preciso explicitar que a direção dessa base técnica está polarizada, ao longo da história, em um projeto conservador e em outro de ruptura, cuja mobilização e luta pela ampliação da sua noção como um direito exige novos olhares e novas práticas teóricas e técnicas para sua efetivação.

O assistente social como conselheiro governamental ocupa um posto privilegiado no acesso às infor- mações que, além da participação nos conselhos, permite trabalhar nas secretarias de assistência social ou unidades ligadas a elas, como os Centros de Referência da Assistência Social (CRAS). O acelerado avanço acadêmico do Serviço Social no âmbito das políticas sociais e da assistência social habilitou essa categoria a desempenhar esse protagonismo nos debates e nas decisões em torno da formulação, implementação e avaliação da política social (PAULO NETTO, 2008).

\subsection{Assistente social como representante da sociedade civil}

Muito se contribuiu para a indefinição da trajetória da assistência social vinculada à prestação de serviços e benefícios com o viés de benesse, sentimento cristão, dever moral e caridade. Desde a aprovação da LOAS (BRASIL, 1993a) e dos Conselhos de Assistência Social, a sociedade civil passou a ser chamada a participar nas decisões e nas fiscalizações da política de assistência social.

No entanto, ao longo do tempo, inúmeros questionamentos vêm se apresentando em relação à qualidade da participação e dos serviços prestados à população. Tatagiba (2002, p. 58) destaca que "para muitos representantes da sociedade civil, estar nos conselhos é uma forma de conseguir mais recursos para suas entidades e não uma forma de construir coletivamente o que seria de interesse público em cada área específica."

O papel do assistente social conselheiro, independentemente do segmento representado, é conduzir os interesses particulares e institucionais para o campo dos interesses públicos, comuns a todos. Além disso, sua atuação nos conselhos é fomentar a participação dos usuários, exercer o controle democrático por meio de comissões e articular-se a outros conselheiros e movimentos sociais para que as decisões tomadas nos CMAS resultem em políticas democráticas, para não se tornar um burocrata das demandas localizadas.

Os assistentes sociais, comprometidos com um projeto societário mais amplo, vêm lutando em diferentes frentes e de diversas formas para defender e reafirmar os direitos e as políticas sociais. Nesse sentido, Abreu (2002) chama atenção para o papel de educador social dos assistentes sociais, com uma "função pedagógica" própria da profissão. O desafio profissional é buscar responder às demandas da população com o compromisso no projeto ético-político da profissão através de princípios e valores fundados na concepção de superação das desigualdades sociais, com direitos sociais universais na (re)afirmação da cidadania, ou seja, no seu caráter emancipatório.

A linguagem é outra característica do papel educativo do assistente social, pois deve propiciar maior 
qualificação da participação, colaborando para a compreensão das demandas locais e desmistificando as questões políticas existentes no espaço dos conselhos.

De Marco (2000) destaca que no desenvolvimento da ação profissional é necessária a utilização de diversas formas de linguagem como: teatral, vídeo e o trabalho de valorização da cultura popular, para que haja um diálogo que facilite questionamentos, críticas, reflexão e proposições resultantes do espaço dos conselhos.

A atuação profissional nos conselhos gestores deve contribuir para a modificação das relações sociais e políticas resgatando a soberania popular. No entanto, para que esse processo de fato se concretize, torna-se necessária a presença de certos elementos na esfera pública que de acordo com Raichelis (1998) são:

a) a visibilidade das ações e dos discursos dos sujeitos expressos com transparência;

b) o controle social que envolve o acesso aos processos de informação das decisões da sociedade;

c) a representação de interesses coletivos que implica a constituição de sujeitos sociais ativos, presentes na cena pública a partir da qualificação de demandas coletivas;

d) a democratização que remete à ampliação dos fóruns de decisão política extrapolando os condutos tradicionais de representação e permite incorporar novos sujeitos sociais como protagonistas e contribuir para criar e consolidar novos direitos; $\mathrm{e}$

e) a cultura pública que supõe o enfrentamento do autoritarismo social e da "cultura privatista" e a apropriação do público pelo privado.

Tais questões remetem à construção de mediações sociopolíticas dos interesses dos sujeitos sociais a serem reconhecidos, representados e negociados na cena visível da esfera pública.

$\mathrm{O}$ assistente social conselheiro exerce seu trabalho num campo privilegiado, pois atua no campo da formulação e do controle social na execução das políticas sociais. Trata-se de uma oportunidade de adensar e qualificar o desempenho profissional que ajude a direcionar e pautar sua intervenção na perspectiva ética da profissão.

\subsection{Assistente social como assessor/consultor}

Outra forma de inserção do assistente social presente na pesquisa é a prestação de assessoria ou de consultoria em matéria de Serviço Social.

Muito tem se falado sobre assessoria e consultoria como atribuições privativas do assistente social, tomando como referência a Lei de Regulamentação da Profissão (BRASIL, 1993b). Nesse caso, podese identificar o exercício profissional de assessoria ou de consultoria como competências profissionais. Segundo Bravo (2009, p. 407),
[...] considera-se que a assessoria às instâncias públicas de controle democrático articulada aos movimentos sociais é um espaço de trabalho que os assistentes sociais podem contribuir para o fortalecimento dos sujeitos políticos na perspectiva da garantia e/ou ampliação dos direitos sociais, tendo no horizonte a emancipação humana.

De acordo com Matos (2006, p. 31-32), a assessoria/consultoria em Serviço Social é "aquela ação que é desenvolvida por um profissional como conhecimento na área que toma a realidade como objeto de estudo e detém uma intenção de alteração de realidade". No entanto, a autora faz uma ressalva sobre o papel do assessor que não deve intervir, mas propor alternativas, pois os assessorados possuem o poder de decisão e a autonomia perante suas escolhas. Além disso, destaca uma diferença entre assessoria e consultoria. $\mathrm{Na}$ primeira o profissional que está prestando assessoria é visto como auxiliar ou "ajudante". Na segunda ele é aquele que emite um parecer sobre o assunto.

Atualmente, o Serviço Social vem sendo requisitado a prestar o serviço de assessoria e de consultoria na gestão de políticas sociais, no setor privado e em movimentos sociais. Os dados da pesquisa apontam que dos 152 assistentes sociais, presentes nos CMAS do estado do Rio de Janeiro, 25 estão na posição de assessor/ consultor $^{4}$ (em valores percentuais são 16,45\%).

A atuação profissional de assessoria e consultoria nos conselhos gestores tem por objetivo colaborar com os conselheiros apontando limites e possibilidades. Pode-se considerar o diagnóstico social como a primeira ação profissional capaz de atender as particularidades das questões sociais junto às políticas públicas em âmbito municipal.

Fonseca (2006, p. 68) aponta uma questão importante no que se refere à relação entre o assessor e os assessorados no processo de trabalho:

\begin{abstract}
$\mathrm{O}$ assessor contribui por ser um agente externo e ter um olhar diferenciado e especializado sobre a questão problemática, enquanto o assessorado contribui com o mapeamento das demandas e a facilitação das informações mais íntima a ele em sua rotina, necessária a desconstrução do problema.
\end{abstract}

Segundo Vasconcelos (1998, p. 132-133), o trabalho de assessoria e de consultoria "busca uma totalização no processo de prática no sentido de apontar, resgatar e trabalhar as deficiências, os limites, recursos e possibilidades da equipe". Para tanto, requer um assistente social qualificado a pensar a prática e a contrapô-la à realidade; e assim sanar a fratura entre a teoria e a prática, compreendendo esse processo dialético de forma crítica e propositiva para que se obtenham resultados que se aproximem da realidade. 
O assistente social na função de assessoria e consultoria nos espaços dos conselhos gestores precisa ser um profissional, como aponta Iamamoto (1998, p. 144-145), "culto e atento às possibilidades descortinadas pelo mundo contemporâneo, capaz de formular, avaliar e recriar propostas ao nível das políticas sociais e da organização das forças da sociedade civil". Além disso, a versatilidade é necessária como instrumento técnico-operativo capaz de realizar ações que hoje são postas como competência profissional.

\section{À guisa de conclusão}

A aposta na possibilidade de uma atuação conjunta do Estado e da sociedade civil emergiu principalmente durante a década de 1990 com o surgimento dos conselhos gestores de políticas públicas. Esse processo é concomitante à ênfase neoliberal, caracterizada pelo desmonte da coisa pública, como a desconstrução dos direitos sociais, com a redução do Estado, a redução dos recursos governamentais e a fragilização das relações do mundo do trabalho.

É nessa conjuntura contraditória que se inscrevem as políticas públicas, especialmente a política de assistência social, com uma forte tendência à refilantropização. Diante desse quadro, o assistente social se vê cotidianamente frente a desafios na sua prática profissional, precisando firmar seu posicionamento ético-político diante da sociedade. É com base nessa afirmação que a atuação profissional nos conselhos deve contribuir para a modificação das relações sociais, considerando os direitos de cidadania e resgatando a soberania popular. Esta é uma relação que precisa ser entendida como um processo educativo, uma vez que cabe ao profissional estimular a participação popular para que o espaço dos conselhos seja percebido através da noção do público e democrático.

Para Bravo e Matos (2006), é possível apontar algumas possibilidades de democratização dos espaços públicos:

a) a percepção dos conselhos na dinâmica da relação entre Estado e sociedade civil; b) a valorização dos movimentos sociais com relevantes para constituição da cidadania; e

c) a clareza de que os conselhos não substituem os movimentos sociais e nem os partidos políticos.

Dessa forma, o assistente social precisa estar atento às possibilidades que vão se descortinando, buscando formular, avaliar e criar propostas capazes de realizar ações, estimulando a socialização das informações e a participação dos usuários. Abreu (2002, p. 212) compreende a função pedagógica do assistente social na perspectiva de emancipação, ou seja,

\begin{abstract}
[...] na medida em que representa um possível conduto de politização dos usuários em relação a sua realidade de vida e serviços institucionais e busca alterar a qualidade dos mesmos, e mais do que isso, como alternativa de fortalecimento de segmentos das classes subalternas na perspectiva da alteração da correlação de força a seu favor e de resistência política.
\end{abstract}

Outro desafio profissional é a função do assistente social como conselheiro (governamental ou da sociedade civil), pois contempla uma faceta de seu exercício profissional que é intrínseco à dimensão política de sua formação. O profissional deve buscar desenvolver um trabalho coletivo que não pode prescindir de articulações e alianças com outros atores sociais. Abreu (2002) mostra que o assistente social precisa estar atento às contradições existentes nos conselhos, pois, caso contrário, ele pode reforçar o projeto hegemônico, contribuindo com a despolitização da questão social e de toda luta liderada pelos movimentos sociais.

Nesse sentido, o profissional de Serviço Social precisa buscar novas estratégias a fim de superar os obstáculos institucionais. Não se pode deixar de mencionar que o espaço institucional também é um local de interesses e de luta por distintos projetos societários que convivem em disputas por hegemonia ${ }^{5}$ nos termos gramscianos.

Tal realidade põe diversos desafios aos assistentes sociais. Dentre esses, compreender e priorizar o espaço dos conselhos e direcionar sua interven- 
ção com novas competências na formulação de políticas públicas, tendo como horizonte a consolidação da cidadania através da democracia, equidade e justiça social, princípios estes preconizados no projeto ético-político da profissão. É nesta direção que Iamamoto (1998, p. 80) ressalta que "Os assistentes sociais, apesar do pouco prestígio e dos baixos salários, formam uma categoria que tem ousado sonhar, que tem ousado ter firmeza na luta, que tem ousado resistir aos obstáculos, porque aposta na história, construindo o futuro, no presente".

\section{Referências}

ABREU, M. M. Serviço Social e a organização da cultura: perfis pedagógicos da prática profissional. São Paulo: Cortez, 2002.

BIDARRA, Z. S. Os conselhos gestores de políticas públicas e a construção de processos democrático-participativos. In: SEMINÁRIO NACIONAL DE POLÍTICAS SOCIAIS NO BRASIL, 2, 2005, Cascavel. Anais... Cascavel: Unioeste, 2005.

BRASIL. Presidência da República. Lei Orgânica da Assistência Social. Lei n. 8.742, de 7 de dezembro de 1993a. Disponível em: <http://www.planalto.gov.br/ccivil 03/leis/18742.htm>. Acesso em: 17 dez. 2011.

Presidência da República. Lei n. 8.662 de 1993b. Disponível em: <http://www.planalto.gov.br/ccivil 03/leis/ L8662.htm>. Acesso em: 17 dez. 2011.

. Política Nacional de Assistência Social. 2004. Disponível em: $\langle$ http://www.sedest.df.gov.br/sites/300/382/00000877.pdf $>$. Acesso em: $10 \mathrm{dez} 2011$.

. Ministério de Desenvolvimento Social e Combate à Fome, 2012a. Disponível em: 〈www.mds.gov.br〉. Acesso em: 10 fev. 2012.

Instituto Brasileiro de Geografia e Estatística, 2012b. Disponível em: 〈www.ibge.gov.br〉. Acesso em: 10 fev. 2012.

BRAVO, M. I. S. O trabalho do assistente social nas instâncias públicas de controle democrático. In: CFESS-ABEPSS. Serviço Social: direitos sociais e competências profissionais. Unidade IV: O significado do trabalho do assistente social nos distintos espaços sócio-ocupacionais. Brasília: Cfess/Abepss, 2009, p. 393-410.

BRAVO, M. I. S.; MATOS, M. C. O potencial da contribuição do Serviço Social na assessoria aos movimentos sociais pelo direito à saúde. In: (Org.). Assessoria, consultoria e

Serviço Social. Rio de Janeiro: 7 Letras, 2006, p. 151-183.

CFESS. Assistentes sociais no Brasil. Elementos para o estudo do perfil profissional. Brasília: Cfess, 2005.
Parâmetros para atuação de assistentes sociais na política de assistência social. Brasília: Cfess, 2010. (Série: Trabalho e projeto profissional nas políticas sociais).

Seminário Nacional: O controle social e a consolidação do Estado democrático de direito. Brasília: Cfess, 2011.

DAGNINO, E. Sociedade civil, participação e cidadania: de que estamos falando? In: MATO, D. (Coord.). Políticas de ciudadania y sociedad civil en tiempos de globalización. Caracas: Faces, Universidad Central de Venezuela, 2004, p. 95-110.

DE MARCO, P. de S. Orçamento participativo: lócus do fazer político-pedagógico. In: CFESS-ABEPSS. Capacitação em Serviço Social e política social: o trabalho do assistente social e as políticas sociais, módulo 4. Brasília: CEAD, 2000.

FONSECA, T. M. A. Análise da literatura profissional sobre a temática da assessoria. In: BRAVO, M. I. S.; MATOS, M. C. (Org.). Assessoria, consultoria e Serviço Social. Rio de Janeiro: 7 Letras, 2006, p. 62-87.

GOMES, A. L. Os conselhos de políticas e de direitos. In: CFESSABEPSS. Capacitação em Serviço Social e política social: o trabalho do assistente social e as políticas sociais, módulo 4. Brasília: CEAD, 2000.

GRAMSCI, A. Concepção dialética da história. Tradução de Carlos Nelson Coutinho. Rio de Janeiro: Civilização Brasileira, 1978.

IAMAMOTO, M. V. O Serviço Social na contemporaneidade: trabalho e formação profissional. São Paulo: Cortez, 1998.

Os espaços sócio-ocupacionais do assistente social. In: CFESS-ABEPSS. Serviço Social: direitos sociais e competências profissionais. Unidade IV: O significado do trabalho do assistente social nos distintos espaços sócio-ocupacionais. Brasília: Cfess/Abepss, 2009, p. 341-376.

Serviço Social em tempo de capital fetiche: capital financeiro, trabalho e questão social. São Paulo: Cortez, 2010.

LENARDÃO, E. O clientelismo na construção do domínio político local: Estudo de caso. 1999. Dissertação (Mestrado em Sociologia) - Universidade Estadual de Campinas, Unicamp, 1999.

MATOS, M. de C. Assessoria e consultoria: reflexões para o Serviço Social. In: BRAVO, M. I. S.; MATOS, M. C. (Org.). Assessoria, consultoria e Serviço Social. Rio de Janeiro: 7 Letras, 2006, p. 29-61.

NEVES, A. V. Espaços públicos participativos, construção democrática e política pública: riscos de despolitização da sociedade civil na cultura política brasileira. Revista Ser Social, $\mathrm{n}$. 17, p. 197-218, jul./dez. 2006. 
Cultura política e democracia participativa: um estudo sobre o orçamento participativo. Rio de Janeiro: Gramma/Faperj, 2008.

PAULO NETTO, J. A construção do projeto ético-político do Serviço Social frente à crise contemporânea. In: CFESS-ABEPSS. Capacitação em Serviço Social e política social: crise contemporânea, questão social e Serviço Social, módulo 1. Brasília: CEAD, 1999.

Prefácio. In: MOTA, A. E. (Org.). O mito da assistência social: ensaios sobre Estado, política e sociedade. São Paulo: Cortez, 2008.

RAICHELIS, R. Esfera pública e conselhos de assistência social: caminhos da construção democrática. São Paulo: Cortez, 1998.

TATAGIBA, L. Os conselhos gestores e a democratização das políticas públicas no Brasil. In: DAGNINO, E. (Org.). Sociedade civil e espaços públicos no Brasil. São Paulo: Paz e Terra, 2002, p. 47-103.

VASCONCELOS, A. M. Relação teoria-prática: os processos de assessoria e consultoria no Serviço Social. Serviço Social \& Sociedade, São Paulo: Cortez, n. 56, p. 114-134, mar. 1998.

\section{Notas}

1 Para Dagnino (2004), a década de 1990 é marcada por uma "confluência perversa" entre projetos societários. A autora destaca os projetos democrático popular e neoliberal: o projeto democrático popular, fortalecido através das lutas sociais no contexto das décadas de 1970 e 1980 e consagrado pela Constituição de 1988, possui como diretriz o aprofundamento da democracia, que se expressa na criação e consolidação de espaços públicos participativos e na crescente participação da sociedade civil nos processos de discussão e tomada de decisão em âmbito público. A sociedade, a partir deste projeto, deve ser capaz de intervir no Estado. Já o projeto neoliberal busca romper com a concepção de participação popular, defendida pelo projeto democrático-popular.

2 O projeto da pesquisa, desenvolvido até o momento, Controle democrático e espaços públicos: a participação da sociedade civil nos Conselhos de Assistência Social, foi aprovado em agosto de 2010, através do processo CNPq 401298/2010-8.

3 Segundo Iamamoto (1998, p. 123), o setor público tem sido o maior empregador de assistentes sociais, "sendo a administração direta a que mais emprega, especialmente nas esferas estadual, seguida da municipal", ressaltando, assim, a necessidade de maior atenção à questão regional e ao poder local.

4 Ressaltamos que os consultados na aplicação do questionário, apesar de serem conselheiros, não necessariamente eram assistentes sociais, por isso não foi possível realizar a distinção entre o trabalho de assessoria e consultoria de acordo com a diferenciação de Matos (2006).

5 O conceito de hegemonia no pensamento gramsciano é concebido como "direção", ou seja, como conquista, através da persuasão e do consenso, não atuando apenas no âmbito econômico e político da sociedade, mas também sobre o modo de pensar, sobre as orientações ideológicas e inclusive sobre o modo de conhecer. A hegemonia é a capacidade de unificar através da ideologia e de conservar unido um bloco social, não se restringindo ao aspecto político, mas compreendendo um fato cultural, moral, de concepção do mundo. Gramsci (1978, p. 37) ainda ressalta que toda relação de hegemonia é "necessariamente uma relação pedagógica, que se verifica não apenas no interior de uma nação, entre as diversas forças que a compõem, mas em todo campo internacional e mundial, entre conjuntos de civilizações nacionais e continentais."

\section{Angela Vieira Neves}

angelaneves@unb.br

Doutora em Ciências Sociais pela Universidade Estadual de Campinas (Unicamp)

Professora do Departamento de Serviço Social da Universidade de Brasília (UnB)

Coordenadora do Grupo de Pesquisa Democracia, Sociedade Civil e Serviço Social (Gepedss)

\section{Cláudia de Oliveira Vicente Santos}

claudinhavicente@yahoo.com.br.

Graduada em Serviço Social pela Universidade Federal Fluminense (UFF)

Assistente social na Associação de Integração de Deficientes Físicos (Assidef)

Pesquisadora do Gepedss

\section{Suellem Henriques da Silva}

suellemhen@hotmail.com

Mestre em Ciência Política pelo Programa de PósGraduação em Ciência Política (PPGCP/UFF) Pesquisadora do do Gepedss

\section{UnB - Gepedss}

Campus Universitário Darcy Ribeiro

Asa Norte, Bloco B, sala B1, 436/463

Brasília - Distrito Federal

CEP: 70910-900 